\title{
AÇÕES E REFLEXÕES SOBRE O USO DE UM GRUPO DE WHATSAPP TUTORIADO PARA APRENDIZAGEM DE LÍNGUA ESTRANGEIRA
}

\section{Gabriela MARQUES-SCHÄFER* Deborah MELLO*}

- RESUMO: Na Didática de Línguas Estrangeiras, o potencial de tecnologias móveis vem sendo cada vez mais investigado. As vantagens dessas tecnologias vão além dos fatos de apresentarem baixo custo, alta conectividade e portabilidade. Trata-se de aparelhos que podem ser acessados e usados por alunos em qualquer lugar a qualquer hora, independente de permissóes de professores e instituiçóes de ensino. Diante desta nova situação, objetivase com este trabalho relatar sobre um Projeto de E-Tutoria que contou com o suporte do aplicativo WhatsApp. Através da formação de um grupo, alunos de um curso de Letras, Português-Alemão, puderam praticar conhecimentos linguísticos adquiridos em sala, interagir sobre seu cotidiano em língua estrangeira e enviar mensagens e arquivos de imagens. Além disso, os alunos puderam contar com o apoio de uma tutora virtual e de uma professora para conseguir se expressar na língua-alvo, tirar dúvidas de gramática e vocabulário e ainda receber feedback corretivo, quando solicitado.

- PALAVRAS-CHAVE: Tutor virtual. Tecnologias móveis. Smartphone. WhatsApp. Feedback. Aprendizagem de línguas.

\section{Introdução}

Aparelhos eletrônicos móveis, como celulares do tipo smartphones e tablets, se tornaram instrumentos de comunicação e organização indispensáveis em nossas vidas pessoais e profissionais. Também na área da educação, as tecnologias móveis vem ganhando cada vez mais espaço. Alguns professores ainda veem a presença desse tipo de tecnologia como uma fonte de distração e algumas instituiçóes de ensino até proíbem qualquer tipo de recurso tecnológico em sala de aula. Porém, alguns estudos como os da Unesco $(2014 a, 2014 b)$ mostram que as tecnologias móveis são capazes de ampliar

\footnotetext{
* Universidade do Estado do Rio de Janeiro. Centro de Educaçâo e Humanidades - Instituto de Letras. Rio de Janeiro - RJ - Brasil. 20559-900 - gabrielamarques@yahoo.com

** Universidade do Estado do Rio de Janeiro. Centro de Educação e Humanidades - Instituto de Letras. Rio de Janeiro - RJ - Brasil. 20559-900 - deborahmarcellino@hotmail.com
} 
e enriquecer oportunidades educacionais em diversos contextos. Telefones celulares e tablets já estão sendo usados por alunos e professores não só para acessar informaçóes, mas também para simplificar a administração da vida pessoal e profissional, assim como promover a aprendizagem de maneira inovadora.

$\mathrm{Na}$ área de ensino e aprendizagem de línguas, o potencial das tecnologias móveis já vem sendo explorado tanto dentro quanto fora da sala de aula. Aplicativos de dicionários e vocabulário estão cada vez mais presentes no cotidiano de alunos e professores. Para a Didática de Línguas Estrangeiras, o importante, no momento, é desenvolver projetos pedagógicos que explorem os benefícios das tecnologias móveis, promovam uma aprendizagem híbrida e aproveitem a competência midiática já existente por parte de muitos dos alunos.

Acreditando no potencial didático do aplicativo de troca de mensagens WhatsApp e com o intuito de testar os desafios e possibilidades do trabalho com tecnologias móveis no ensino de línguas estrangeiras, foi desenvolvido um Projeto de E-Tutoria via WhatsApp, para uma disciplina do curso de graduação em Letras, Português-Alemão, da Universidade do Estado do Rio de Janeiro. O objetivo do presente artigo é apresentar este Projeto e discutir seus primeiros resultados.

A seguir, discorreremos sobre o uso do aplicativo WhatsApp para aprendizagem de línguas e sobre o papel do professor/ tutor em ambientes virtuais de aprendizagem. Depois da descriçẫo do Projeto, passaremos à análise dos dados levantados a partir das interaçóes realizadas através do aplicativo e de questionários respondidos pelos participantes.

\section{O uso do WhatsApp para aprendizagem de línguas}

Uma das tecnologias móveis que cada vez mais ganha destaque na área da Educação e na Didática de Línguas Estrangeiras é o celular do tipo smartphone. Com suas inúmeras funções de organização e comunicação, este tipo de aparelho já substitui, em alguns contextos, o uso de outros recursos tecnológicos como o computador e o CD-Player.

Dentre os aplicativos mais usados no mundo através dos smartphones, um deles merece atenção por parte dos professores de línguas devido às suas funçóes de comunicação e compartilhamento de informaçóes e materiais multimidiáticos. Trata-se do aplicativo WhatsApp que a partir da possibilidade de troca de mensagens de texto e áudio, assim como de envio de imagens, vídeos e da realização de chamadas vem, aos poucos e em determinados contextos, substituindo o uso de SMS e E-Mails. Este aplicativo já conta com cerca de "900 milhóes de usuários" (WHATSAPP, 2015b) e cerca de "30 bilhôes de mensagens instantâneas enviadas por dia” (WHATSAPP, 2015a). Além disso, o WhatsApp conta também com a versão WhatsApp Web que permite aos usuários trocar mensagens com seus contatos utilizando o computador no lugar do celular, através de sua conta do aplicativo. 
Souza (2015) criou um grupo no WhatsApp com seus alunos de inglês como língua estrangeira para promover o ensino híbrido, ou seja, aquela forma de ensino que combina encontros presenciais com atividades mediadas por tecnologia. $\mathrm{O}$ propósito de seu projeto também era criar pares de interação comunicativa, uma vez que o professor enviava, através do aplicativo, questóes para serem solucionadas em casa que seriam posteriormente aprofundadas em sala de aula. Dessa forma, esperava-se que o tempo em sala de aula ficasse mais reservado para as trocas sobre o conteúdo e não para uma exposição do conteúdo. Os alunos deveriam fazer um contato prévio e fora da aula com o tema a ser abordado e levar para as aulas suas dúvidas. Souza (2015) destaca a possibilidade de criação de grupos através do WhatsApp que, em sua opinião, foi responsável pela criação de um espaço virtual interativo e colaborativo, o qual pode servir de apoio ao processo de ensino e aprendizagem de línguas.

No estudo de Gutiérrez-Colon et al. (2013), alunos de inglês como língua estrangeira usaram o aplicativo WhatsApp para interagirem sobre textos enviados através de links e discutirem questóes de compreensão e interpretação. Segundo os autores, os alunos consideraram a troca de mensagens como uma ferramenta atraente e inovadora para aprendizagem, pois podiam escrever e receber mensagens curtas e de forma imediata. Os autores notaram ainda que, após o projeto, houve um aumento na motivaçáo por parte dos alunos para a realizaçáo de atividades de leitura na língua estrangeira (no caso o inglês).

Kaieski, Grings e Fetter (2015) realizaram uma pesquisa-ação em uma turma de um curso de inglês de nível intermediário e em uma disciplina de um curso técnico em informática. Em ambos os contextos foram criados grupos separados via WhatsApp que foram usados para que os alunos pudessem tirar dúvidas e interagir sobre o conteúdo programático de seus cursos. Os resultados da investigaçáo mostram que o aplicativo contribuiu para a promoçáo de um maior engajamento, uma maior participação e colaboraçáo dos alunos no processo de ensino e aprendizagem dentro e fora da sala de aula.

Já Leite e Silva (2015) buscaram, através de uma pesquisa sobre interaçôes em grupo via WhatsApp, caracterizar as trocas de mensagens como um gênero textual. Segundo as autoras, os participantes da pesquisa, usaram não só o serviço de troca de mensagens de texto como um chat tradicional, mas também outras funçôes midiáticas oferecidas pelo aplicativo, como o envio de imagens e áudios. A partir daí as autoras puderam observar uma sobreposição de linguagens, que vai além da utilização da linguagem verbal e vai até o uso de uma linguagem imagética e sonora. Além disso, as autoras detectaram o forte uso de uma linguagem informal, justificada pelo fato dos participantes tentarem se aproximar ao máximo da linguagem usada em situaçóes orais do cotidiano e recorrerem com frequência ao uso de gírias e emoticons.

De fato, o número de estudos sobre o aplicativo WhatsApp na área da Didática de Línguas Estrangeiras ainda é bastante reduzido, porém pode-se concluir, a partir de relatos já publicados (RAMBE e BERE, 2013; AMRY, 2014; BOUHNIK; DESHEN, 
2014), que seu uso pode contribuir para elevar a participação dos estudantes em discussóes sobre um determinado tema ligado a uma disciplina/ um curso, aumentar a motivação para aprendizagem, melhorar o compartilhamento de informaçóes e conhecimentos, promover a aprendizagem sócio-construtivista, fomentar a autoconfiança dos estudantes, favorecer a resoluçáo de problemas e criar um ambiente de aprendizagem virtual agradável, próximo à realidade dos estudantes e de baixo custo.

\section{O papel do tutor virtual}

Dentro da área da Didática de Línguas Estrangeiras, a discussão sobre o papel de tutores virtuais é bastante ampla. É possível encontrar diversas nomenclaturas que vão desde "tutor online" ou "tele-tutor" até "e-tutor", "e-moderador", "tutor virtual", "facilitador" ou "coach". Schnaithmann (2008, p. 46) afirma que essas nomenclaturas são usadas, muitas vezes, como sinônimos e que é muito difícil apontar diferenças entre elas, uma vez que o fator decisivo para a compreensão do papel de um tutor que trabalha em um contexto virtual é justamente a investigação do seu contexto de atuação. Dessa forma, mais importante do que escolher o termo é decidir as funçóes que a pessoa terá que exercer. É preciso se perguntar se o professor/ tutor terá encontros presenciais com os alunos, se ele será responsável pela seleção de temas, textos e conteúdos, pelo acompanhamento virtual dos alunos, pelas avaliaçóes e pelas formas e tipos de feedback.

Para Schnaithmann $(2008$, p. 46) aqueles professores que organizam e realizam cursos totalmente online e ainda orientam alunos em contexto virtual assumem o papel de "professores online". Já aqueles que ficam responsáveis somente pela orientação virtual de alunos, respondendo a perguntas e explicando alguns temas de determinados conteúdos, devem ser vistos como "tutores online" ou "acompanhantes de aprendizagem online".

Rösler (2004, p. 196) trabalha com dois termos ao tentar classificar os tipos de serviços de tutoria que vem sendo oferecidos por editoras de livros didáticos e instituiçốes de ensino de línguas: "tutor online" e "tutor virtual". Segundo o autor, "tutor online" são aqueles profissionais que estão ligados a um material, programa ou curso online, trabalham de forma anônima, corrigem respostas e textos de alunos, mas não tem uma relação pessoal com eles. Já o "tutor virtual" seria aquele profissional que é conhecido entre os alunos através de foto(s), de um perfil com informaçóes gerais sobre sua pessoa e estão disponíveis para responder a dúvidas relacionadas ao processo de aprendizagem de línguas.

A partir de um estudo sobre o papel de tutores em contexto de aprendizagem de alemão como língua estrangeira, Rösler e Würffel (2010) descrevem as seguintes competências necessários para atuação em ambientes virtuais: (i) a competência da disciplina em questão que se relaciona ao domínio do tutor de conhecimentos teóricos e práticos da área; (ii) competência metodológica que se refere à capacidade do tutor de escolher métodos e materiais adequados ao seu contexto de atuação; (iii) competência 
organizacional que engloba a habilidade do tutor de organizar conteúdos, datas, avaliaçóes e outros compromissos que levam ao sucesso na organização do curso; (iv) competência administrativa que trata da capacidade do tutor de administrar desde o suporte técnico até o tempo reservado para a realização de determinadas tarefas; (v) competência social e pessoal que diz respeito à habilidade do tutor de se relacionar pessoalmente com os alunos, estabelecendo contato, promovendo momentos de interação tutor-aluno(s) e aluno(s)-aluno(s) e trabalhando a motivação; (vi) competência didática que se refere à capacidade do tutor de negociar, selecionar e tratar determinados temas, passar e formular atividades e exercícios, fomentar as quatro habilidades (leitura, escrita, fala e escuta), promover a aprendizagem de gramática e vocabulário, assim como elaborar feedback que contribua de forma positiva para aprendizagem; (vii) e competência midiática ${ }^{1}$ que trata da habilidade do tutor de lidar com diferentes recursos tecnológicos em prol do processo de ensino e aprendizagem.

Para o presente trabalho, podemos afirmar, de acordo com a definição sugerida por Rösler (2004), que o grupo tutoriado criado através do aplicativo WhatsApp contou com a participação de uma tutora virtual, uma vez que os alunos a conheceram através de fotos e de uma visita presencial feita à sala da disciplina da qual os alunos frequentavam (Língua Alemá III). Quanto ao seu papel, cabe informar que a tutora ficou responsável por responder a perguntas dos alunos e moderar as interaçôes. Vale destacar ainda que não era de sua responsabilidade a organização, administração nem avaliação do curso presencial frequentado pelos alunos da turma, uma vez que ela também ainda era aluna de graduaçáo, porém já do oitavo período. Dessa forma, esperava-se da tutora que ela apresentasse uma competência da disciplina, no caso competência em língua alemã, sendo capaz de se comunicar de forma correta e fluente no idioma estrangeiro. Além disso, esperava-se também dela competência social, pessoal, didática e midiática para se relacionar e se comunicar bem com os participantes, assim como produzir feedback adequado ao nível dos alunos.

\section{Sobre o Projeto de E-Tutoria}

Partimos de um princípio teórico construtivista e interacionista de que é por meio de interações autênticas e espontâneas que alunos podem apresentar mais facilidade para aprender uma língua estrangeira (VYGOTSKY, 1978; LONG, 1981; PICA,

\footnotetext{
De acordo com o Rösler (2004, p. 125), o conceito de competência midiática deve ser visto a partir de duas perspectivas: a da recepçáo e a da produção de textos digitais. Para o autor, uma pessoa que tenha competência midiática dispóe da habilidade de receber, buscar, analisar e criticar qualquer tipo de informaçáo, texto, vídeo e áudio em formato digital. Além disso, ela é capaz de produzir textos digitais de forma oral ou escrita em diferentes canais, como Chat, E-Mail, Fórum e outros, uma vez que conhece suas diferentes dinâmicas, técnicas e funçôes. Alguém que apresenta competência midiática sabe não só agir bem de forma social no mundo digital, mas também é capaz de criar e desenvolver páginas virtuais, podcasts, vídeos, aplicativos etc.
} 
1994; HENRICI, 1995). Dessa forma, optamos pela criação de um grupo tutoriado via WhatsApp que viesse a ter semelhanças com outros chats didáticos já conhecidos e investigados (PLATTEN, 2003; REBELO, 2006; ARAÚJO E SÁ; MELLO-PFEIFFER, 2009; BIEBIGHÄUSER; MARQUES-SCHÄFER, 2009; MARQUES-SCHÄFER, 2013), uma vez que esses são capazes de promover interaçóes autênticas e espontâneas em contexto de aprendizagem de língua.

O Projeto de E-Tutoria ${ }^{2}$ via WhatsApp, realizado no primeiro semestre de 2015, objetivou não só promover uma maior integração entre a turma e aumentar a motivação pela aprendizagem de alemáo, mas também oferecer aos alunos uma oportunidade de praticar a língua estrangeira de forma dinâmica, autêntica e espontânea fora da sala de aula.

Participaram do Projeto onze estudantes da disciplina de Língua Alemã III, do curso de Letras, Português-Alemão, da Universidade do Estado do Rio de Janeiro (UERJ). Nós, autoras do presente artigo, também participamos das interaçōes no grupo do aplicativo na qualidade de tutora e professora, sendo esta a professora da disciplina em questáo e aquela uma aluna do oitavo período. Devido à sua responsabilidade pelo desenvolvimento e avaliação do Projeto, a professora optou por observar mais as interações, enquanto que a tutora, além de atuar como moderadora, ficou mais responsável por responder a perguntas de gramática e de significado de palavras e expressóes.

Ficou acordado entre o grupo que todos deveriam escrever, em alemão, o máximo que conseguissem e, em português, o mínimo necessário. Além disso, foi pedido que mensagens só fossem enviadas entre às 8 e 22 horas e que se tratassem somente do tema do Projeto. ${ }^{3}$

Durante aproximadamente dois meses, os alunos realizaram a tarefa de levar para casa o pelúcia do Grüffelo, personagem principal de uma obra da literatura infantil internacionalmente conhecida, o Grüffelo, de Donaldson e Scheffler (2012) e relatar através do WhatsApp sobre sua rotina. A cada semana, um aluno deveria enviar mensagens de texto e voz, fotos e vídeos. Além disso, foi combinado entre os alunos e a professora que, para o final do semestre, cada aluno deveria entregar um trabalho final sobre o Projeto, em formato de texto, áudio ou vídeo, que apresentasse algumas das experiências da turma com o Grüffelo.

\section{Metodologia de pesquisa e análise dos dados}

A presente investigação é de base qualitativo-interpretativista. Pode-se também situála como uma pesquisa-ação, uma vez que uma das autoras desempenhou, ao mesmo

\footnotetext{
2 Trata-se de um Sub-Projeto do Grupo de Pesquisa CALIC-TECH da UERJ. Disponível em: <www. calic.uerj.br>. Acesso em: 21 set. 2016.

3 Esse combinado foi realizado em sala de aula antes do início das trocas de mensagens via aplicativo.
} 
tempo, uma dupla função, a de professora e pesquisadora em um mesmo contexto. Segundo Caspari, Helbig e Schmelter (2007), a pesquisa-ação é uma forma de trabalho adotada por professores de línguas que, objetivando compreender melhor questóes ligadas à sala de aula, investigam suas próprias açóes, seus materiais e todos os envolvidos no processo de ensino-aprendizagem.

Para o presente estudo foram elaborados dois questionários distintos que foram respondidos pelos alunos antes e depois da realização do Projeto. Ambos os questionários continham perguntas abertas e fechadas e tinham como objetivo levantar dados sobre a relaçáo dos alunos com o uso de tecnologias móveis e sobre suas experiências ao longo da duraçáo do Projeto de E-Tutoria. Além disso, a tutora também respondeu a um questionário ${ }^{4}$, através do qual ela pôde fazer uma reflexão sobre sua atuação como tutora online.

A seguir, apresentaremos, primeiramente, algumas sequências das interaçóes no grupo e uma discussão sobre a perspectiva da tutora acerca do Projeto e, posteriormente, analisaremos os dados coletados entre os alunos. Focaremos nossa análise nos dados que tratam especificamente sobre questôes ligadas às funçôes da tutora e à correção de erros.

\section{Exemplos de sequências interacionais em grupo tutoriado via WhatsApp}

As interaçôes realizadas no grupo tutoriado via WhatsApp assemelham-se a interaçóes ocorridas em chats didáticos como as analisadas em Marques-Schäfer (2013). As mensagens são enviadas de forma quase sempre sincrônica e apresentam um formato curto. Outra característica comum entre os chats didáticos e as conversas em grupo tutoriado via WhatsApp é o entrelaçamento temático das mensagens trocadas, o que às vezes dificulta a fluidez da conversa e o entendimento entre os participantes.

Os alunos participantes do Projeto de E-Tutoria buscavam escrever de forma correta, respeitando as regras de gramática e ortografia da língua alemã. Os exemplos 1 e 2 a seguir ilustram a tentativa dos alunos de corrigir seus próprios erros:

Exemplo 1:

8:00 AM - Aluno A: Ja, wir haben eine gute Nacth. Grüffelo ist sehr zufrieden.

8:03 AM - Aluno A: Hatte*

8:04 AM - Tutora: Hahaha! Sehr gut! Er sieht ein bisschen böse aus,aber das stimmt nicht, oder?

8:05 AM - Tutora: Wo hast du diese Korrektur gemacht? (Hatte)

\footnotetext{
As quatro perguntas deste questionário foram: (i) explique como você realizava sua tarefa como tutora no grupo?; (ii) Em algum momento, você se sentiu insegura para moderar e/ou corrigir?; (iii) como você vê a questão da correção dentro de um grupo via WhatsApp para fins de aprendizagem de língua?; e (iv) Na sua opiniáo, qual foi/ quais foram os benefícios do projeto tanto para você como futura professora quanto para os alunos?
} 
8:06 AM - Aluno A: Ich weiße nicht, (estou um pouco confusa, não sabia se colocava a frase no presente ou no passado.

Exemplo 2:

12:30 PM - Aluno B: Wo?

12:30 PM - Aluno B: :((

12:30 PM - Aluno C: Im internet ist billinger

12:30 PM - Aluno C: billiger *

Este comportamento de busca pela forma gramatical e ortográfica correta mostra a preocupaçáo dos alunos em se comunicar sem erros mesmo fora da sala de aula. Alguns alunos desejavam saber concretamente onde estavam seus erros e perguntavam diretamente a Tutora por ajuda. A tutora, por sua vez, adotava modos de correçáo indireta, como pode-se observar a partir do Exemplo 3:

Exemplo 3:

6:25 PM - Aluno E: Nein, sie ist ein Freund. Wir studiert zusammen.

6:26 PM - Aluno E: **einen

6:26 PM - Tutora: Ah ok eine Freundin von dir :-) sie sieht dir ähnlich aus

A tutora além de moderar as conversas e ajudar com questóes linguísticas e interculturais, também desempenhava um papel de boa colega, demostrando compreensão e apoio quando alguém relatava sobre alguma dificuldade. No Exemplo 4 a seguir uma aluna relata sobre suas dificuldades com a interferência do inglês na sua aprendizagem de alemáo. A tutora reage comentando sobre sua própria experiência e manifestando apoio. A aluna responde, reconhecendo as palavras da tutora como um estímulo:

Exemplo 4:

8:55 AM - Aluno A: Gut, ich schlecht nicht fühlen

8:55 AM - Aluno A: ( a última frase é pela questão do inglês)

8:57 AM - Aluno B: Ich möchte englisch vergessen (Esquecer)

8:58 AM - Aluno A: Ich auch

8:58 AM - Tutora: Ich fühle mich nicht mehr schlecht

9:02 AM - Tutora: Ihr habt letztes Jahr angefangen deutsch zu lernen...es ist noch etwas neu!Am Ende dieses Semester fangt ihr mehr auf deutsch zu denken!

9:02 AM - Tutora: Ihr könnt schon gut verstehen und das ist super!

9:07 AM - Aluno A: Ich kann verstehen. Das Problem kommt später. 
9:11 AM - Tutora: Das ist ganz normal!

9:12 AM - Tutora: Am Anfang könnte ich gut verstehen, aber fast nichts sagen

9:16 AM - Aluno A: Ah ja, gut ist ein Anreiz(estímulo é assim mesmo ?)

\section{A perspectiva da tutora}

A perspectiva da tutora sobre o Projeto de E-Tutoria via WhatsApp foi investigada a partir dos dados levantados com um questionário composto de quatro perguntas abertas sobre sua experiência como tutora, o desafio na elaboração de feedback corretivo e sua visão sobre os benefícios do Projeto para sua formaçáo universitária como professora de língua alemã. A tutora afirma que, apesar de já ter tido experiência como docente em contexto presencial, a participação no Projeto na qualidade de tutora virtual significou um desafio para sua formação, uma vez que ela mesma nunca tinha participado de um curso ou projeto que envolvesse o uso de tecnologias na área de ensino e aprendizagem de línguas nem nunca tido ouvido falar sobre o potencial didático do aplicativo WhatsApp.

Quanto à questão das correçôes, a tutora mostrou-se insegura sobre quando, como e com que frequência corrigir quais tipos de erros:

Tutora: Quanto às correçôes, posso dizer que me sentia bastante insegura no começo. Eu não me sentia segura sobre a forma e o momento correto de fazê-las. Como eu só conhecia os participantes do projeto de vista, no começo não pude planejar uma forma de correção mais individualizada como é possível fazer dentro de sala de aula. E, além disso, minhas correçóes deviam ser feitas de forma breve para que nenhuma explicação se perdesse devido a conversas cruzadas.

A tutora menciona ainda sua preocupação em não inibir os alunos com as correçôes e relata que preferia estimulá-los a se comunicar mais no grupo a ter que se ocupar com a formulação de feedbacks corretivos. $\mathrm{Na}$ opiniāo da tutora, que ainda é aluna de graduação, o projeto de E-Tutoria via WhatsApp traz diferentes benefícios para sua futura profissão como professora. A tutora afirma ter conseguido, através do Projeto, desenvolver senso crítico acerca da problemática de elaboração de feedback corretivo em ambiente virtual de aprendizagem. Na opinião da tutora-aluna, ela teve também a oportunidade de aperfeiçoar conhecimentos sobre a língua-alvo e experimentar novas técnicas de correção. Além disso, a tutora considerou como um importante benefício poder colaborar para a formação de outros alunos, uma vez que, através das interações no grupo via aplicativo, ela pôde relatar sobre suas experiências com o processo de aprendizagem de alemáo e incentivar os colegas a continuarem os estudos. A tutora pondera ainda que com o Projeto passou a ter mais consciência da importância do constante aprendizado fora da sala de aula.

Posteriormente, a tutora ainda foi solicitada a relatar por E-Mail sobre a possibilidade técnica de seu smartphone de alterar o teclado do português para o alemão para se 
comunicar no grupo. A tutora afirma ter feito utilização desse recurso, uma vez que este a ajudava a digitar algumas letras do alfabeto alemão, como ä, ö, ü e ß. Esse resultado confirma que a tecnologia móvel traz um fato novo para estudos na área da Didática de Línguas Estrangeiras que é o uso de um recurso digital na comunicação simultânea dos alunos, facilitando o uso da forma correta da língua em questão.

\section{A perspectiva dos alunos}

Através de questionários de Pré- e Pós-Pesquisa, pudemos investigar a perspectiva dos alunos acerca do uso de tecnologias móveis no processo de aprendizagem de língua alemã e acerca de suas experiências e opinióes sobre o Projeto de E-Tutoria via WhatsApp na UERJ em que participaram. Onze estudantes integraram o grupo, porém só sete responderam aos questionários. Dentre as respostas obtidas, somente quatro alunos afirmaram já terem ouvido falar do uso de tecnologias móveis no ensino de línguas. Enquanto somente um aluno afirmou já ter feito uso de tecnologias móveis dentro da sala de aula de alemão, ou outros seis afirmam usar este tipo de recurso somente fora da sala de aula.

Um aluno ao responder, relatou sobre sua experiência em sala e explicou que faz uso de um aplicativo de dicionário para procurar palavras do livro didático que não conhece. Quanto ao uso de tecnologias móveis fora da sala de aula, os alunos informaram que já usam tecnologias móveis como smartphones e tablets para treinar vocabulário, revisar gramática, ouvir música e pesquisar na Internet.

No questionário Pós-Pesquisa, os alunos foram solicitados a relatar sobre suas estratégias de comunicação diante de situações em que não entendiam alguma palavra ou expressão em língua estrangeira usada no grupo por algum dos participantes. Os alunos afirmam que diante deste tipo de situação fizeram uso de dicionários impressos e digitais, inclusive através do próprio celular, além de terem feito perguntas diretas ao grupo a fim de tirar dúvidas e descobrir os significados das palavras ou expressóes usadas.

Com o intuito de verificar se algumas dessas novas palavras ou expressóes ficaram na memória dos alunos, foi perguntado se eles poderiam citar espontaneamente alguma e indicar a razão pela qual eles ainda conseguiam se lembrar da palavra ou expressão citada. Cinco dos sete alunos que responderam ao questionário foram capazes de listar algumas palavras, como Stau (engarrafamento), Drillingen (trigêmeos) e Spitzname (apelido) e afirmaram que as situaçóes relatadas pelos colegas no grupo e as fotos enviadas ajudaram na memorização.

Este resultado confirma o pressuposto teórico em que o presente estudo se baseia. Partimos do princípio que situaçóes reais de interação em língua estrangeira sobre temas do cotidiano dos alunos podem contribuir para a aprendizagem. Além disso, este resultado mostra que a visualização de imagens com o pelúcia do Grüffelo em tais situações contribui para o processo cognitivo de memorização de novo vocabulário. 
Diversas das fotos enviadas ao grupo mostravam um pouco da vida pessoal dos participantes fora da sala de aula. Os alunos foram solicitados a informar sua opinião sobre tal exposição e todos afirmaram que o envio de fotos pessoais para um grupo com fins de aprendizagem foi interessante e proporcionou uma maior aproximação entre os colegas na vida real. Todos afirmaram terem gostado do compartilhamento de informaçóes e fotos sobre o dia-a-dia dos colegas.

Quanto aos momentos de correção, quatro dos seis alunos, que responderam à questão se foram corrigidos e como foi a correção, disseram que se lembram de terem sido corrigidos e os outros dois não conseguiram lembrar de nenhuma situação. Um aluno traz à luz um dos desafios do momento de realização de correçáo, uma vez que este pode ser delicado tanto para quem a faz quanto para aquele que a recebe:

Aluno C: As correçôes foram bem tranquilas e claras; mas se quem for corrigido não estiver aberto a isso, a correçáo pode ser mal interpretada (a pessoa pode achar que o corretor está querendo "aparecer").

Dos sete questionários respondidos, somente quatro alunos relataram como se sentiram ao receber a correçáo. Três desses alunos afirmaram que gostaram e ficaram satisfeitos com o feedback corretivo. O aluno C, porém, comenta que no início apresentou dificuldades com as correçóes:

Aluno C: Num momento, eu confesso que fiquei irritada por estar sendo corrigida o tempo todo, mas depois eu comecei a aceitar as correçôes melhor.

Cabe mencionar que não foram encontradas correçóes de erros de alunos feitas por um outro aluno. Todos os feedbacks corretivos partiram da tutora e, em alguns casos, da professora, e foram realizados de forma indireta e/ ou após um pedido explícito de ajuda. Entretanto, deve-se também lembrar que nem todos os erros de gramática e ortografia puderam - e nem deveriam - ser corrigidos para que o fluxo da comunicação não fosse interrompido. Como todos os alunos tinham a mesma função no grupo, poderíamos esperar que algum produzisse feedback corretivo com relação a algum erro de algum outro colega. Tal tipo de situação não foi encontrada e um dos alunos aborda esta questão em sua resposta, afirmando ter percebido o erro dos colegas, mas decidido náo corrigir por não estar seguro nem ter certeza de que a correção era desejada.

Aluno F: Percebi erros que não foram corrigidos e não me senti "à vontade" ou até mesmo segura para corrigir o colega.

Quanto à questão do recurso tecnológico oferecido pelos aparelhos de smartphones de instalar teclados de diferentes línguas e obter correção ortográfica e sugestão de palavras, seis dos sete alunos que responderam ao questionário de Pós-Pesquisa afirmaram ter feito 
uso deste recurso. Alguns alunos justificaram suas decisóes devido a fatores práticos, como explica o seguinte aluno:

Aluno B: Durante o projeto em si, no grupo do whatsapp, fiz uso do teclado em alemão, pelo simples motivo de que, se não usasse o teclado em alemáo, teria que usar algum dos outros teclados que tenho habilitados (português, inglês e espanhol). No meu telefone, é impossível NÃO ter um teclado de uma língua específica; não existe um teclado geral, sem idioma. Então, caso não usasse o teclado alemão, em primeiro lugar não teria acesso aos caracteres especiais do alemáo, porque os outros teclados não os têm, e em segundo lugar, teria que usar um teclado de alguma outra língua que consideraria todas as palavras que eu escrevesse incorretas e ficaria tentando consertar cada uma delas para que virassem palavras daquela língua. Ou seja, eu teria que basicamente lutar contra o teclado a cada palavra. Não era prático, principalmente tendo a opção de simplesmente utilizar o teclado em alemão.

Já um outro aluno afirma ter recorrido também ao dicionário para poder ter certeza da grafia correta das palavras:

Aluno F: Algumas vezes tive dúvida com a grafia correta de algumas palavras e utilizei o corretor por ser fácil e rápido, porém algumas vezes precisei consultar o dicionário para ter certeza, pois algumas palavras tem a grafia parecida.

Um único aluno afirmou não ter trocado o idioma do teclado para se comunicar no grupo por não se sentir familiarizado com este recurso:

Aluno H: Não. Eu não recorri ao uso dessa ferramenta dos smartphones quando participei do projeto, pois na época eu ainda não era muito familiarizada com essa ferramenta existente nos celulares, por isso, preferi fazer uso do dicionário, que é uma ferramenta de muita importância e que nos ajuda de várias formas, como informaçôes que vão do significado das palavras até a forma correta de se pronunciar.

Este resultado mostra que a experiência de trocar o idioma do teclado pode ser vista por alguns alunos como um desafio para o ato da escrita em língua estrangeira. Quanto ao recurso tecnológico de sugestão de palavras oferecidos pelos aparelhos de smartphones, nenhum dos alunos afirmaram ter feito uso desta opçáo ao escrever no grupo tutoriado via Whats $A p p$. $\mathrm{O}$ aluno $\mathrm{C}$ afirma ter se sentido inseguro quanto a esta possibilidade, uma vez que para aceitar a sugestão automática de uma palavra é preciso ter certeza de que a palavra sugerida é justamente a que o aluno estava procurando ou tentando escrever:

Aluno C: Eu usei sim o teclado na versão em alemão e achei bom porque dava para saber se a palavra estava correta. Já em relação às palavras novas que ele sugere, eu não 
cheguei a usar porque eu não me sentia segura e ficava com medo de o significado ser diferente do que eu pensei mesmo quando eu olhava na internet.

Dos sete alunos que responderam ao questionário Pós-Pesquisa, seis afirmam que o projeto os motivou a estudar mais alemão. Todos os sete afirmaram ter gostado de poder ler e escrever mais no idioma estrangeiro. Além disso, todos manifestaram vontade de participar de outro projeto que envolvesse o uso de tecnologias móveis ao ensino e recomendariam o Projeto de E-Tutoria para aplicação em outras turmas.

Quando solicitados a resumir suas experiências no Projeto, os alunos listaram as seguintes palavras: incentivador, interessante, educativo, dinâmico, alegre, instigante, inovador, útil, estimulante e lúdico.

\section{Conclusões e encaminhamentos}

Neste artigo, discutiu-se o uso do recurso de formação de grupo no aplicativo Whats $A p p$ para contexto de ensino e aprendizagem de línguas. Diante dos resultados aqui apresentados, pode-se concluir que as tecnologias móveis já fazem parte da rotina de aprendizagem de língua estrangeira dos alunos fora da sala de aula e que o Projeto de E-Tutoria via WhatsApp da UERJ pode ser visto como uma experiência pioneira que une o uso tecnologia móvel a projeto pedagógico previamente elaborado de uma disciplina de graduação.

Os dados mostraram que o Projeto de E-Tutoria foi avaliado de forma bastante positiva tanto pela tutora quanto pelos alunos e que serviu como motivação para praticar conhecimentos linguísticos adquiridos em sala de aula. Além disso, pôdese perceber a partir dos dados, que os alunos participantes do Projeto optaram por somente enviar mensagens de texto e imagens, deixando de lado outros recursos do aplicativo já tão usados em interaçôes em língua materna no dia-a-dia, como o envio de mensagens de áudio e vídeos. Acredita-se que os alunos ainda não se sintam seguros quanto à sua competência linguística em língua estrangeira para se expressar de forma oral em um grupo e expor eventuais dificuldades. Assim, pode-se pensar para trabalhos futuros em desenvolver estratégias que motivem os alunos a tentar se expressar também através de áudios e vídeos como forma de praticar suas habilidades de fala e aprimorar a fluência.

Quanto à questão do feedback corretivo, pode-se concluir, a partir da análise de sequências interacionais e de relatos dos participantes, que estamos diante de um desafio já bem conhecido dentro da área da Didática de Línguas Estrangeiras: Como, quando e por que realizar correçóes? Os dados levam-nos a concluir que para a realização de projetos em grupo via WhatsApp com fins de aprendizagem de língua estrangeira é necessário encontrar um equilíbrio entre a necessidade de correção, o desejo (ou não) de obter correção por parte dos alunos e a fluência da comunicação. É recomendável definir previamente com os alunos quais são os objetivos do projeto, 
da comunicação e quais papéis cada um deve assumir dentro do grupo afim de evitar frustraçóes, mal-entendidos e interrupçóes constantes ao longo das interaçóes ligadas ao tema proposto.

Por fim, este trabalho mostra que o aplicativo em questáo traz não só funçóes tecnológicas inovadoras e atraentes para a educação e para o ensino de línguas, mas também possibilita a realização de algo inédito até o momento no âmbito da produção de textos. Graças aos novos recursos, hoje é possível produzir textos escritos de forma síncrona e móvel, utilizando um sistema digital automático de correção e sugestão de palavras, algo que até então só era possível em situaçóes de produção de texto de forma assíncrona em um computador. Dessa forma, seria importante a realizaçáo de novos estudos que investiguem mais a fundo as estratégias de redação e colaboração dos alunos em interaçóes mediadas a partir do WhatsApp para fins de aprendizagem de línguas.

\section{ACTIONS AND REFLECTIONS ON THE USE OF A WHATSAPP GROUP FOR FOREIGN LANGUAGE LEARNING}

- ABSTRACT: The potential of mobile technology is being increasingly investigated. The advantages of these technologies go beyond the low-cost, high connectivity and portability. These are devices that can be accessed and used by students anywhere at any time, regardless of permissions teachers and educational institutions. Given this new situation, the purpose of this work is to report on an E-Mentoring Project which had the support of the WhatsApp application. By forming a group, students of Portuguese and German could practice language skills acquired in the classroom, interact about their daily lives in a foreign language and send messages and images files. In addition, students could count on the support of a virtual tutor and a teacher to be able to express in the target language, ask questions of grammar and vocabulary and still receive corrective feedback when requested.

- KEY WORDS: Virtual tutor. Mobile technologies. WhatsApp. Feedback. Language learning.

\section{REFERÊNCIAS}

AMRY, A. B. The Impact of whatsapp mobile social learning on the achievement and attitudes of female students compared with face to face learning in the classroom. European Scientific Journal, [S.l.], v.10, n 22, p. 116-136, 2014.

ARAÚJO E SÁ, M. H.; MELO-PFEIFER, S. Co-construcción de saberes lingüísticos en los chats plurilingües en lenguas románicas. In: LÓPEZ ALONSO, C.; BARRIO, M. M. del. (Org.). Las plataformas de aprendizaje. Madrid: Biblioteca Nueva, 2009. p. 225-251. 
BIEBIGHÄUSER, K.; MARQUES-SCHÄFER, G. DaF-Lernen online: Die Chat-Angebote des Goethe-Instituts. JETZT Deutsch lernen und Second Life: InfoDaF, [S.I.], v. 5, n.36, p.411-428, 2009.

BOUHNIK, D.; DESHEN, M. Whatsapp goes to school: mobile instant messaging between theachers and students. Journal of Information Technology Education: Research, [S.l.], v.13, p. 217-231, 2014.

CASPARI, D.; HELBIG, B.; SCHMELTER, L. Forschungsmethoden: explorativinterpretatives Forschen. In: BAUSCH, K.-R.; CHRIST, H.; KRUMM, H.-J. (Org.). Handbuch Fremdsprachenunterricht. 5. aufl ed. Tübingen: A. Francke, 2007. p.499-506.

DONALDSON, J.; SCHEFFLER, A. Der Grüffelo. Erfurt: Beltz \& Gelberg, 2012.

GUTIÉRREZ-COLON, P. et al. Improving learners' reading skills through instant short messages: a sample study using WhatsApp. Global perspectives on Computer-Assited Language Lerning. 4 ed. Glasgow: Scottish Exhibition Center in Glasgow, 2013. p.80-84.

HENRICI, G. Spracherwerb durch Interaktion. 5 ed. Baltmannsweiler: Schneider Verlag Hohengehren, 1995.

KAIESKI, N.; GRINGS, J. A.; FETTER, S. A. Um estudo sobre as possibilidades pedagógicas de utilização do WhatsApp. Revista Novas Tecnologias na Educaçáo, Porto Alegre, v. 13, p.1-10, 2015.

LEITE, N. C.; SILVA, M. O. WhatsApp: caracterizaçáo do gênero chat em contexto de ensino de línguas estrangeiras. Textolivre, Belo Horizonte, v. 8, n. 1, p. 85-97, 2015.

LONG, M. H. Input, interaction, and second-language acquisition. Annals of the New York Academy of Sciences, [S.1.], v.379, p.259-278, 1981.

MARQUES-SCHÄFER, G. Deutsch lernen online: eine analyse interkultureller interaktionen in einem didaktisierten Chat. Tübingen: Narr, 2013.

PICA, T. Research on negotiation: what does it reveal about second-language learning conditions, processes and outcomes? Language Learning, [S.1.], v.44, n.3, p. 493-527, 1994.

PLATTEN, E. Chat-tutoren didaktischen chat-raum. sprachliche hilfen und moderation. In: LEGUTKE, M.; RÖSLER, D. (Org.). Fremdsprachenlernen mit digitalen Medien. Tübingen: Narr, 2003. p.145-177.

RAMBE, P.; BERE, A. Using mobile instant messaging to leverage learner participation and transform pedagogy at South African University of Technology. British Journal of Educational Technology, London, v.44, n. 4, p. 544-561, 2013. 
REBELO, I. M. Interação em ambientes virtuais: negociação e construção de conhecimento em Português como Segunda Língua. 2006. 248f. Tese (Doutorado em Letras) - Pontifícia Universidade Católica do Rio de Janeiro, Rio de Janeiro, 2006.

RÖSLER, D. E-Learning Fremdsprachen: eine kritische Einführung. Stauffenburg, Tübingen, 2004.

RÖSLER, D.; WÜRFFEL, N. Online-Tutoren: kompetenzen und ausbildung. Tübingen, Narr, 2010.

SCHNAITHMANN, A. Online-sprachtutoren ausbilden. München: Langenscheidt, 2008.

SOUZA, C. F. de. Aprendizagem sem distância: tecnologia digital móvel no ensino de língua inglesa. Texto Livre: Linguagem e Tecnologia, Belo Horizonte, v. 8, n.1, p. 39-50, 2015.

UNESCO. Reading in the mobile era: a study of mobile reading in developing countries. Paris, 2014a. Disponível em: <http://unesdoc.unesco.org/images/0022/002274/227436E. pdf>. Acesso em 17 mar. 2016.

UNESCO. Diretrizes de políticas da UNESCO para a aprendizagem móvel. Paris, $2014 \mathrm{~b}$. Disponível em: <http://unesdoc.unesco.org/images/0022/002277/227770por.pdf>. Acesso em: 17 mar. 2016.

VYGOTSKY, L. S. Mind in society: the development of higher psychological processes. Cambridge: Harvard University Press, 1978.

WHATSAPP atinge os 700 milhóes de usuários por mês em todo mundo. G1, São Paulo, 07 jan. 2015a. Disponível em: <http://g1.globo.com/tecnologia/noticia/2015/01/whatsapp-atingeos-700-milhoes-de-usuarios-por-mes-em-todo-o-mundo.html>. Acesso em: 07 jan. 2015.

WHATSAPP chega a 900 milhões de usuários. G1, São Paulo, 04 nov. 2015b. Disponível em: <http://g1.globo.com/tecnologia/noticia/2015/09/whatsapp-chega-900-milhoes-de-usuarios. html>. Acesso em: 04 set. 2015.

Recebido em 31/03/2016

Aprovado em 05/07/2016 